\title{
Perioperative Dexamethasone and Post-Rhinoplasty Edema: A Prospective Observational Study
}

\author{
Ali Abdullah Alshehri \\ Assistant Professor, ORL \& HNs and Facial Plastic Surgery, College of Medicine, Najran University, \\ Najran, Kingdom of Saudi Arabia \\ Email: aaalshehrie@nu.edu.sa
}

How to cite this paper: Alshehri, A.A. (2022) Perioperative Dexamethasone and Post-Rhinoplasty Edema: A Prospective Observational Study. International Journal of Otolaryngology and Head \& Neck Surgery, 11, 1-11.

https://doi.org/10.4236/ijohns.2022.111001

Received: October 29, 2021

Accepted: December 4, 2021

Published: December 7, 2021

Copyright $\odot 2022$ by author(s) and Scientific Research Publishing Inc. This work is licensed under the Creative Commons Attribution International License (CC BY 4.0).

http://creativecommons.org/licenses/by/4.0/

(c) (i) Open Access

\begin{abstract}
Purpose: The timing, schedule, and doses of dexamethasone administration to control edema are a topic of debate. This prospective observational study was performed to evaluate the effects of perioperative and intraoperative administration of dexamethasone on the occurrence of edema in patients who underwent rhinoplasty. Methods: This study was conducted at Najran University Hospital, Najran University, Saudi Arabia, from June 2019 to August 2020. Seventy-five patients who underwent open rhinoplasty were assigned using a consecutive non-random sampling method into three groups, with 25 patients in each group. Group A patients received three doses of intravenous $8 \mathrm{mg}$ dexamethasone perioperatively, and group B patients received a single dose of intravenous $8 \mathrm{mg}$ dexamethasone intraoperatively. Group C patients received intravenous $2 \mathrm{~mL}$ of $0.9 \%$ normal saline solution intraoperatively and were considered as a control group. Digital photographs of patients were obtained and assessed on the $1^{\text {st }}, 7^{\text {th }}$, and $14^{\text {th }}$ days post-operatively. Results: The mean duration of operation was comparable between the studied groups $(\mathrm{p}=0.368)$. On comparing the studied groups, significant differences in the edema scores were observed on the $1^{\text {st }}$ and $7^{\text {th }}$ day post-operatively $(\mathrm{p}<0.001$ for both), but not on the $14^{\text {th }}$ day $(p=0.079)$. When comparing each group against the postoperative day of evaluation, statistically significant differences were detected between the $1^{\text {st }}$ vs. $7^{\text {th }}$ day and $1^{\text {st }}$ vs. $14^{\text {th }}$ day in Group A, whereas, in the other groups, no significant difference was detected (all $\mathrm{p}>0.05$ ). No Dexamethasone-related complications were observed. Conclusion: Dexamethasone significantly reduced periorbital swelling and edema after rhinoplasty compared to the control group. A short course of triple dose perioperative administration of dexamethasone is more potent in reducing edema from $1^{\text {st }}$ to $7^{\text {th }}$ day postoperative than a single dose intraoperatively.
\end{abstract}


Keywords

Dexamethasone, Administration, Dosage, Periorbital Swelling, Edema, Rhinoplasty

\section{Introduction}

Rhinoplasty is a common, popular, and challenging cosmetic procedure routinely performed in the domains of otolaryngology, maxillofacial, and plastic surgery [1]. According to the American Society of Plastic Surgeons statistics report, rhinoplasty is the fourth most common cosmetic surgical procedure of 2019 [2]. Rhinoplasty involves controlled trauma to the bone in the form of lateral osteotomies in the vestibular-nasal complex. This massive manipulation of the tissue and injury to the angular vessels lead to undesirable yet inevitable postoperative edema and ecchymosis in the periorbital region [3]. This can be unappealing and cause concern, anxiety, and dissatisfaction amongst the patients treated with rhinoplasty. Edema can reduce the visual acuity also contribute to delay the healing. On the other hand, ecchymosis can elevate the social apprehensions of the patient and may lead to permanent pigmentation [4] [5].

To reduce this primary adverse effect of postoperative edema associated with rhinoplasty, various drugs, mechanisms, and techniques have been investigated. Drugs such as corticosteroids, tranexamic acid, decongestants, fibrin sealants, lignocaine with adrenaline, natural herbal products such as Arnica Montana, papaya extract papain have also been recommended. Specific mechanisms such as nasal packing, tapping, postoperative heal elevation, cold application, intraoperative hypotension, drainage tubes have also been investigated to reduce edema in the postoperative period. Some modifications in the traditional rhinoplasty technique such as subperiosteal tunneling, piezotome, sharp micro-osteotome, preserving periosteal attachment have also been reported in various literatures [6]. All these methods have been experimented with variable success rates. However, there is a lack of consensus among surgeons regarding the most effective modality to control the edema and ecchymosis associated with rhinoplasty [7] [8].

Nevertheless, corticosteroids remain the mainstay in managing postoperative complications by reducing the swelling, bruising, and recovery time. Steroids act by reducing vascular permeability, leading to less exudation of tissue fluid and decreased edema. This happens through a cascade of inflammatory responses involving fibrin deposition, capillary dilation, migration of lymphocytes, and phagocytic activity [9].

Dexamethasone is the most common and suitable corticosteroid used clinically due to its inexpensive availability, highest anti-inflammatory response, early-onset action, and long biological half-life of 36 - 72 hours [10]. Since prescribed for the short-term, they are associated with negligible adverse effects and 
do not compromise with patients' safety [11]. The timing, schedule, and doses of dexamethasone administration to control edema have been a topic of debate. Thus, this prospective observational study was performed to evaluate the effects of perioperative and intraoperative administration of dexamethasone on the occurrence of edema in patients treated with rhinoplasty.

\section{Material and Methods}

This prospective cohort study was conducted at the College of Medicine, Najran University, Kingdom of Saudi Arabia, between June 2019 and August 2020. We followed the Strengthening the Reporting of Observational Studies in Epidemiology (STROBE) statement guidelines when reporting this manuscript [12]. The study protocol was approved by the Research Ethics Committee of Najran University, Kingdom of Saudi Arabia (Reference No.: 442-42-52381-DS). The study was conducted in accordance with the Helsinki Declaration of 1964, as revised in 2013 [13]. Written and informed consent form was obtained from each patient.

\subsection{Eligibility Criteria}

Adult patients (aged between 18 and 50 years) of both genders who were operated for open rhinoplasty were included in the current study. We excluded patients with a history of coagulation disorders, diabetes mellitus, peptic ulcer, hypertension, tuberculosis, previous rhinoplasty, body dysmorphic disorder, glaucoma, and known allergy to steroids.

\subsection{Study Groups, Procedures, and Measurements}

A consecutive non-random sampling method was used to recruit patients. The current study included three groups of patients. Group A included 25 patients who received three doses of $8 \mathrm{mg}$ dexamethasone intravenous (IV) perioperatively, and group B included 25 patients who received a single dose of $8 \mathrm{mg}$ dexamethasone IV intraoperatively. Group C included 25 patients who received $2 \mathrm{~mL}$ of $0.9 \%$ normal saline solution IV intraoperatively as a control group.

Demographic data, including age, gender, duration of surgery (minutes), and duration of anesthesia (minutes), were recorded for each patient. All patients were operated on by me using a similar technique. Operations were performed in general anesthesia with endotracheal intubation, and $5 \mathrm{~mL}$ of $1 \%$ lidocaine with 1:100,000 adrenaline was additionally infiltrated at the osteotomy sites. Propofol 2 - $3 \mathrm{mg} / \mathrm{kg}$, rocuronium $0.6 \mathrm{mg} / \mathrm{kg}$ and fentanyl $50-75 \mathrm{mcg}$ were administered during induction. Anesthesia was maintained with sevoflurane $2 \%$ in $40 \%-60 \%$ oxygen-air mixture and remifentanil $0.125 \mu \mathrm{g} / \mathrm{kg} / \mathrm{min}$ intravenously. Mean arterial blood pressure was maintained between 90 - $100 \mathrm{mmHg}$ during the procedure, and any complications were recorded. Dorsal hump removal and bilateral lateral osteotomies via transcutaneous approach were performed on each patient. The nasal septum was supported using silastic sheets, and splints were placed for a week. No attempts were made to control the edema during or after 
the surgery with pressure packs or ice packs. All patients received similar postoperative care and instructions, including head elevation 30 - 45 degrees for 48 hours, paracetamol $500 \mathrm{mg}$ four times a day, and antibiotic amoxicillin $500 \mathrm{mg}$ three times a day for seven days.

All patients were discharged on the second day post-operatively and were recalled on the $7^{\text {th }}$ and $14^{\text {th }}$ days for regular follow-up. Digital photographs of patients were obtained on the $1^{\text {st }}, 7^{\text {th }}$, and $14^{\text {th }}$ days post-operatively. Two independent observers assessed the patients' digital photographs and scored the edema as follows: no edema was graded as 0 , mild edema with $0 \%-25 \%$ involvement of the eyelid was graded 1, moderate edema with $25 \%$ - 50\% eyelid involvement covering iris was graded 2, severe edema with 50\% - 75\% eyelid involvement getting to the pupil was graded 3, and inability to open the eye with $>75 \%$ massive eyelid involvement was graded 4 .

\subsection{Statistical Analysis}

All analyses were done using the Statistical Package for Social Science (SPSS software version 20 for Windows). Categorical data were expressed as counts and percentages, while continuous data were presented as mean and standard deviation (SD). For comparison of categorical and continuous data, the chi-square test and one-way analysis of variance (ANOVA) were used as appropriate. The severity of edema between the groups was compared using the Kruskal-Wallis test and within the groups using the Friedman test. A p-value of $<0.05$ was statistically significant.

\section{Results}

\subsection{Characteristics of the Study Population}

A total of 75 patients ( 39 female and 36 male) were photographically evaluated in this study. The mean age was 22.14 years ( $\mathrm{SD}=5.45), 24.66$ years $(\mathrm{SD}=6.73)$, and 25.96 years $(S D=5.17)$ among group $A, B$, and $C$ patients, with no significant difference between the studied groups $(p=0.087)$. The mean duration of operation was comparable between the studied groups; it was 170.42 in group A, 172.84 in group $B$, and 179.56 in group $C(p=0.368)$. Table 1 shows the demographic characteristics of the study groups.

\subsection{Postoperative Periorbital Edema}

Postoperative periorbital edema was assessed on the $1^{\text {st }}, 7^{\text {th }}$ and $14^{\text {th }}$ days following rhinoplasty, as shown in Table 2. Statistically significant differences in the edema scores among the three groups of patients were observed on the $1^{\text {st }}$ and $7^{\text {th }}$ day post-operatively $(40 \%, 48 \%$, and $64 \%$ for day 1 and $20 \%, 36 \%$, and $52 \%$ for day $7 ; \mathrm{p}<0.001$ for both) but not on the $14^{\text {th }}$ day $(12 \%, 16 \%$, and $20 \% ; \mathrm{p}=$ 0.079). When comparing within each group, a statistically significant difference was found in the edema score in the $1^{\text {st }}, 7^{\text {th }}$, and $14^{\text {th }}$ days among the three groups (all $\mathrm{p}<0.001)$. 
Table 1. Demographic characteristic of the studied three groups.

\begin{tabular}{ccccc}
\hline & $\begin{array}{c}\text { Group A } \\
(\mathbf{n}=25)\end{array}$ & $\begin{array}{c}\text { Group B } \\
(\mathbf{n}=25)\end{array}$ & $\begin{array}{c}\text { Group C } \\
(\mathbf{n}=25)\end{array}$ & p-value \\
\hline Age (years) & $22.14 \pm 5.45$ & $24.66 \pm 6.73$ & $25.96 \pm 5.17$ & $0.087^{\alpha}$ \\
Weight (kg) & $65.64 \pm 11.54$ & $68.26 \pm 8.73$ & $66.75 \pm 9.36$ & $0.452^{\alpha}$ \\
Height (cm) & $165.32 \pm 8.85$ & $163.51 \pm 9.11$ & $169.93 \pm 11.61$ & $0.387^{\alpha}$ \\
Gender (M/F) & $13 / 12$ & $12 / 13$ & $11 / 14$ & $0.852^{\beta}$ \\
Duration of operation (min) & $170.42 \pm 16.34$ & $172.84 \pm 15.67$ & $179.56 \pm 16.92$ & $0.368^{\alpha}$ \\
\hline
\end{tabular}

Values are expressed in mean \pm standard deviation or number; ${ }^{a} \mathrm{p}>0.05$ One-way ANOVA between groups; ${ }^{\beta} \mathrm{p}>0.05$ chi-square test between groups; Group A included patients who received three doses of $8 \mathrm{mg}$ dexamethasone IV perioperatively; Group B included patients who received a single dose of $8 \mathrm{mg}$ dexamethasone IV intraoperatively; Group C (control group) included 25 patients who received $2 \mathrm{~mL}$ of $0.9 \%$ normal saline solution IV intraoperatively.

Table 2. Comparison of edema in the studied three groups on $1^{\text {st }}, 7^{\text {th }}$, and $14^{\text {th }}$ days postoperatively.

\begin{tabular}{ccccc}
\hline Edema (upper and lower eyelid) & Group A & Group B & Group C & p-value $^{\alpha}$ \\
\hline Day 1 & $10(40 \%)$ & $12(48 \%)$ & $16(64 \%)$ & $<0.001$ \\
Day 7 & $5(20 \%)$ & $9(36 \%)$ & $13(52 \%)$ & $<0.001$ \\
Day 14 & $3(12 \%)$ & $4(16 \%)$ & $5(20 \%)$ & 0.079 \\
p-value $^{\beta}$ & $<0.001$ & $<0.001$ & $<0.001$ & \\
\hline
\end{tabular}

Values are expressed as frequencies and percentages; ${ }^{\alpha}$ Kruskal-Wallis test; ${ }^{\beta}$ Friedman test; Group A included patients who received three doses of $8 \mathrm{mg}$ dexamethasone IV perioperatively; Group B included patients who received a single dose of $8 \mathrm{mg}$ dexamethasone IV intraoperatively; Group C (control group) included 25 patients who received $2 \mathrm{~mL}$ of $0.9 \%$ normal saline solution IV intraoperatively.

When comparing each group against the postoperative day of evaluation, a statistically significant difference was found between the $1^{\text {st }} v$ vs. $7^{\text {th }}$ day and $1^{\text {st }} v$ vs. $14^{\text {th }}$ day in Group A, whereas, in the other groups, no significant difference was detected (all $\mathrm{p}>0.05$ ). No complications related to the administration of dexamethasone were detected among the study participants.

The details of postoperative edema along the period of study are shown in Table 3. The positive effect of dexamethasone in group A and group B is evident. On day 1, "no edema" was reported in $60 \%, 52 \%$, and $36 \%$, while on day 14 , it was documented for $88 \%, 84 \%, 80 \%$ among group A, B, and C patients, respectively. The inability to open the eye was reported in none of the group $\mathrm{A}$ patients and only one patient of group B on day 1 .

\section{Discussion}

The persistent edema and ecchymosis can change the patients' perception of the procedure and produce a range of negative impactions. Edema post-rhinoplasty 
Table 3. Comparison of edema grades for each group over the period of study.

\begin{tabular}{ccccc}
\hline & Grade & Day 1 & Day 7 & Day 14 \\
\hline Group A $(\mathrm{n}=25)$ & I & $15(60 \%)$ & $20(80 \%)$ & $22(88 \%)$ \\
& II & $4(16 \%)$ & $1(4 \%)$ & $3(12 \%)$ \\
& III & $2(8 \%)$ & $1(4 \%)$ & $0(0 \%)$ \\
& IV & $0(0 \%)$ & $0(0 \%)$ & $0(0 \%)$ \\
\hline Group B $(\mathrm{n}=25)$ & 0 & $13(52 \%)$ & $16(64 \%)$ & $21(84 \%)$ \\
& I & $2(8 \%)$ & $3(12 \%)$ & $3(12 \%)$ \\
& II & $7(28 \%)$ & $4(16 \%)$ & $1(4 \%)$ \\
& III & $2(8 \%)$ & $2(8 \%)$ & $0(0 \%)$ \\
& IV & $1(4 \%)$ & $0(0 \%)$ & $0(0 \%)$ \\
\hline & 0 & $9(36 \%)$ & $12(48 \%)$ & $20(80 \%)$ \\
Group C $(\mathrm{n}=25)$ & I & $2(8 \%)$ & $5(20 \%)$ & $3(12 \%)$ \\
& II & $2(8 \%)$ & $5(20 \%)$ & $1(4 \%)$ \\
& III & $8(32 \%)$ & $2(8 \%)$ & $1(4 \%)$ \\
& IV & $4(16 \%)$ & $1(4 \%)$ & $0(0 \%)$ \\
\hline
\end{tabular}

0 = no edema, $\mathrm{I}=$ mild edema, $\mathrm{II}=$ moderate edema. $\mathrm{III}=$ severe edema, IV = inability to open the eye; Group A included patients who received three doses of $8 \mathrm{mg}$ dexamethasone IV perioperatively; Group B included patients who received a single dose of $8 \mathrm{mg}$ dexamethasone IV intraoperatively; Group C (control group) included 25 patients who received $2 \mathrm{~mL}$ of $0.9 \%$ normal saline solution IV intraoperatively.

could cause post-rhinoplasty dissatisfaction syndrome [14]. Nevertheless, this issue has been actively addressed in the literature, and many studies have been performed to derive an effective solution to reduce the severity of edema in patients who underwent rhinoplasty. This prospective observational study aimed to evaluate the effects of perioperative and intraoperative administration of dexamethasone on the occurrence of edema in patients treated with rhinoplasty.

\subsection{Summary of Main Findings}

In this study, dexamethasone significantly reduced the periorbital edema and swelling in the postoperative period compared to the control group (normal saline). A triple dose perioperative administration of dexamethasone is more potent in reducing edema from the $1^{\text {st }}$ to $7^{\text {th }}$ day than a single dose intraoperatively. However, by the $14^{\text {th }}$ day, the therapeutic effects of steroids wear off, and there is no difference regarding the severity of periorbital edema against the control group.

\subsection{Agreement and Disagreement with the Previous Studies}

The efficacy of corticosteroids to reduce postoperative edema and ecchymosis remains debatable and controversial due to conflicting results of various research 
publications. The first attempt through a prospective randomized controlled trial was made by Griffies et al. in 1989, who concluded that a single dose of $10 \mathrm{mg}$ dexamethasone could significantly reduce facial edema compared to a placebo [5]. Hoffmann et al. reported a significant reduction in periorbital and paranasal edema when $10 \mathrm{mg}$ dexamethasone was used pre-and post-operatively [15]. Moreover, Tuncel et al. reported a similar finding and found that steroids' administration reduced intraoperative bleeding [16]. Kara and Gokalan also reported a reduction in periorbital edema and ecchymosis with $10 \mathrm{mg}$ dexamethasone after two days post-rhinoplasty [17]. In 2018, another study found that preoperative 8 $\mathrm{mg}$ dexamethasone can reduce the periorbital swelling by $50 \%$ compared to $33.3 \%$ in placebo [18]. Totonchi et al. showed that $10 \mathrm{mg}$ dexamethasone reduced edema till postoperative day 2; however, no difference was observed by day 8 [19].

In this study, a triple dose of perioperative dexamethasone would reduce the edema till the $7^{\text {th }}$ day post-operatively, after which the difference is negligible. Previous studies have used superior imaging techniques such as 3D surface scans [20] and found that in patients treated with orthognathic surgeries, $40 \mathrm{mg}$ dexamethasone reduced the facial edema significantly compared to low doses of 5 and $15 \mathrm{mg}$ dexamethasone. A Cochrane review also reported a decrease in ede$\mathrm{ma}$ and ecchymosis with preoperative $10 \mathrm{mg}$ dexamethasone in the first two days post-operatively, after which no difference was observed [21]. Recently, in 2020, two systematic reviews and meta-analyses by Aldhabaan et al. [22] and Bian et al. [23] supported the use of dexamethasone with rhinoplasty. Aldhabaan et al. confirmed significant benefits with preoperative corticosteroids and found that higher doses are associated with a more significant reduction in edema and ecchymosis [22]. However, contrasting results have been shown by Berinstein et al. [24], who used MRI scans and found that dexamethasone administered post-rhinoplasty patients experienced increased edema compared to controls. Gurlek et al. demonstrated that steroids were ineffective in preventing or reducing edema or ecchymosis in patients treated with open rhinoplasty with osteotomy [4].

Dosage and timing of steroid administration for effective edema control after rhinoplasty has been suggested in previous literature. Hatef et al. reported that preoperative dosage was superior to postoperative dosage and extended administration was superior to single bolus dose [25]. Kargi et al reported that a single dose before osteotomy and a triple dose afterward effectively reduced edema after rhinoplasty [26]. Hwang et al. suggested multiple-dose steroid administration against a single dose to reduce post-rhinoplasty associated edema and ecchymosis [27]. A previous meta-analysis documented that steroids decreased postoperative periorbital edema in the first three days, after which they failed to provide any benefits [28].

\subsection{Significance of the Study Findings}

This variation in the effect of dexamethasone with different timings and dosage 
can be attributed to its long half-life, gene expression on the target cells, patient profile, associated morbidity, and the extensiveness of the surgical procedures. The outcome can also differ due to the variable response of the hypothalamic-pituitary-adrenal axis and suppression of the adrenal glands. Moreover, the interference of steroids on the healing of tissue and infection of the surgical site can also be a cause of concern [29]. It also helps in reducing pain and muscle spasms [30]. However, the data is limited, and more clinical evidence is required to establish the clinical effects of herbal supplements and cold applications. Tapping of the nose post-rhinoplasty is another effective method to reduce postoperative edema and ecchymosis. It compresses the bleeding site, eliminates the dead space, prevents septal hematomas, and increases patient satisfaction by providing a fresh look to the nose during the recovery period [31]. In contrast, clinical evidence suggests that nasal packing is ineffective and precipitates complications. Nasal packing compresses nasal capillaries, blocks venous return, and forces blood into the eyelid, leading to increased severity of periorbital edema and ecchymosis [32].

\subsection{Limitations}

This study has a few limitations, including the small sample size and subjective assessment and evaluation method. Superior imaging techniques such as $3 \mathrm{D}$ scanning, MRI, ultrasonography, and stereophotogrammetry can be used to evaluate the extent and intensity of edema post-rhinoplasty; however, we could not assess it. Further investigations can be done employing various other drugs, regimes, schedules, and dosage to better understand the postoperative benefits, complications, associated adverse effects, surgeon satisfaction, and patient outcome.

\subsection{Conclusion}

In conclusion, dexamethasone has significantly reduced periorbital swelling and edema after rhinoplasty compared to the control group. A triple dose perioperative administration of dexamethasone significantly reduced edema from the $1^{\text {st }}$ to $7^{\text {th }}$ day compared to a single dose intraoperatively. However, by the $14^{\text {th }}$ day, there is no difference regarding the effect of steroid administration on the severity of edema. This study supports the use of dexamethasone in rhinoplasty to reduce postoperative complications, associated morbidities and enhance the early recovery of the patients.

\section{Acknowledgments}

Dr. Ali Abdullah Alshehri would like to thank Dr. Ahmed Jalal and Dr. Habib Bashir for their efforts being independent assessors.

\section{Conflicts of Interest}

The author declares no conflicts of interest regarding the publication of this paper. 


\section{References}

[1] Angelos, P.C., Been, M.J. and Toriumi, D.M. (2012) Contemporary Review of Rhinoplasty. Archives of Facial Plastic Surgery, 14, 238-247. https://doi.org/10.1001/archfaci.2012.577

[2] American Society of Plastic Surgeons (2020) Plastic Surgery Statistics Report. Online, 2020-2022.

[3] Toriumi, D.M., Mueller, R.A., Grosch, T., Bhattacharyya, T.K. and Larrabee, W.F. (1996) Vascular Anatomy of the Nose and the External Rhinoplasty Approach. Archives of Otolaryngology_Head \& Neck Surgery, 122, 24-34. https://doi.org/10.1001/archotol.1996.01890130020003

[4] Gurlek, A., Fariz, A., Aydogan, H., Ersoz-Ozturk, A. and Eren, A.T. (2006) Effects of Different Corticosteroids on Edema and Ecchymosis in Open Rhinoplasty. Aesthetic Plastic Surgery, 30, 150-154. https://doi.org/10.1007/s00266-005-0158-1

[5] Griffies, W.S., Kennedy, K., Gasser, C., Fankhauser, C. and Taylor, R. (1989) Steroids in Rhinoplasty. Laryngoscope, 99, 1161-1164. https://doi.org/10.1288/00005537-198911000-00010

[6] Mehdizadeh, M., et al. (2018) Comparison of the Effect of Dexamethasone and Tranexamic Acid, Separately or in Combination on Post-Rhinoplasty Edema and Ecchymosis. Aesthetic Plastic Surgery, 42, 246-252.

https://doi.org/10.1007/s00266-017-0969-x

[7] Ong, A.A., Farhood, Z., Kyle, A.R. and Patel, K.G. (2016) Interventions to Decrease Postoperative Edema and Ecchymosis after Rhinoplasty: A Systematic Review of the Literature. Plastic and Reconstructive Surgery, 137, 1448-1462. https://doi.org/10.1097/PRS.0000000000002101

[8] Kelley, B.P., Koshy, J., Hatef, D., Hollier, L.H. and Stal, S. (2011) Packing and Postoperative Rhinoplasty Management: A Survey Report. Aesthetic Surgery Journal, 31, 184-189. https://doi.org/10.1177/1090820X10395507

[9] Becker, D.E. (2013) Basic and Clinical Pharmacology of Glucocorticosteroids. Anesthesia Progress, 60, 25-32. https://doi.org/10.2344/0003-3006-60.1.25

[10] Jones, R. and Daunt, M. (2014) Should Anaesthetists Routinely Give Dexamethasone as a Perioperative Antiemetic? British Journal of Hospital Medicine, 75, 118. https://doi.org/10.12968/hmed.2014.75.2.118

[11] Brunton, L., et al. (2006) Goodman \& Gilman's: The Pharmacological Basis of Therapeutics. McGraw-Hill, New York. https://doi.org/10.7812/TPP/06-008

[12] von Elm, E., Altman, D.G., Egger, M., Pocock, S.J., Gøtzsche, P.C. and Vandenbroucke, J.P. (2008) The Strengthening the Reporting of Observational Studies in Epidemiology (STROBE) Statement: Guidelines for Reporting Observational Studies. Journal of Clinical Epidemiology, 61, 344-349. https://doi.org/10.1016/j.jclinepi.2007.11.008

[13] World Medical Association (2013) World Medical Association Declaration of Helsinki: Ethical Principles for Medical Research Involving Human Subjects. JAMAJournal of the American Medical Association, 310, 2191-2194. https://doi.org/10.1001/jama.2013.281053

[14] Belek, K.A. and Gruber, R.P. (2014) The Beneficial Effects of Postrhinoplasty Taping: Fact or Fiction? Aesthetic Surgery Journal, 34, 56-60. https://doi.org/10.1177/1090820X13515879

[15] Hoffmann, D.F., Cook, T.A., Quatela, V.C., Wang, T.D., Brownrigg, P.J. and Brummett, R.E. (1991) Steroids and Rhinoplasty: A Double-Blind Study. Archives of Oto- 
laryngology_Head \& Neck Surgery, 117, 990-993. https://doi.org/10.1001/archotol.1991.01870210062009

[16] Tuncel, U., Turan, A., Bayraktar, M.A., Erkorkmaz, U. and Kostakoglu, N. (2013) Efficacy of Dexamethasone with Controlled Hypotension on Intraoperative Bleeding, Postoperative Oedema and Ecchymosis in Rhinoplasty. Journal of Cranio-Maxillofacial Surgery, 41, 124-128. https://doi.org/10.1016/j.jcms.2012.06.003

[17] Kara, C.O. and Gökalan, I. (1999) Effects of Single-Dose Steroid Usage on Edema, Ecchymosis, and Intraoperative Bleeding in Rhinoplasty. Plastic and Reconstructive Surgery, 104, 2213-2218. https://doi.org/10.1097/00006534-199912000-00043

[18] Sanober, A., et al. (2018) Use of Steroids in Rhinoplasty with Lateral Osteotomies for Reducing Post Operative Oedema. Journal of Ayub Medical College Abbottabad, 30, $45-48$

[19] Totonchi, A. and Guyuron, B. (2007) A Randomized, Controlled Comparison between Arnica and Steroids in the Management of Postrhinoplasty Ecchymosis and Edema. Plastic and Reconstructive Surgery, 120, 271-274.

https://doi.org/10.1097/01.prs.0000264397.80585.bd

[20] Semper-Hogg, W., Fuessinger, M.A., Dirlewanger, T.W., Cornelius, C.P. and Metzger, M.C. (2017) The Influence of Dexamethasone on Postoperative Swelling and Neurosensory Disturbances after Orthognathic Surgery: A Randomized Controlled Clinical Trial. Head \& Face Medicine, 13, 19. https://doi.org/10.1186/s13005-017-0153-1

[21] da Silva, E.M.K., Hochman, B. and Ferreira, L.M. (2014) Perioperative Corticosteroids for Preventing Complications Following Facial Plastic Surgery. Cochrane Database of Systematic Reviews, No. 6, CD009697. https://doi.org/10.1002/14651858.CD009697.pub2

[22] Aldhabaan, S.A., Hudise, J.Y. and Obeid, A.A. (2020) A Meta-Analysis of Pre- and Postoperative Corticosteroids for Reducing the Complications Following Facial Reconstructive and Aesthetic Surgery. Brazilian Journal of Otorhinolaryngology, 177182. https://doi.org/10.1016/j.bjorl.2020.05.015

[23] Bian, X., Liu, H., Sun, J., Zhang, X., Li, N. and Chen, M. (2020) Efficacy of Dexamethasone for Reducing Edema and Ecchymosis after Rhinoplasty: A Systematic Review and Meta-Analysis. Aesthetic Plastic Surgery, 44, 1672-1684.

https://doi.org/10.1007/s00266-020-01743-w

[24] Berinstein, T.H., Bane, S.M., Cupp, C.L., DeMarco, J.K. and Hunsaker, D.H. (1998) Steroid Use in Rhinoplasty: An Objective Assessment of Postoperative Edema. Ear, Nose \& Throat Journal, 77, 40-43. https://doi.org/10.1177/014556139807700109

[25] Hatef, D.A., Ellsworth, W.A., Allen, J.N., Bullocks, J.M., Hollier, L.H. and Stal, S. (2011) Perioperative Steroids for Minimizing Edema and Ecchymosis after Rhinoplasty: A Meta-Analysis. Aesthetic Surgery Journal, 31, 648-657. https://doi.org/10.1177/1090820X11416110

[26] Kargi, E., Hoşnuter, M., Babucçu, O., Altunkaya, H. and Altinyazar, C. (2003) Effect of Steroids on Edema, Ecchymosis, and Intraoperative Bleeding in Rhinoplasty. Annals of Plastic Surgery, 51, 570-574. https://doi.org/10.1097/01.sap.0000095652.35806.c5

[27] Hwang, S.H., Lee, J.H., Kim, B.G., Kim, S.W. and Kang, J.M. (2015) The Efficacy of Steroids for Edema and Ecchymosis after Rhinoplasty: A Meta-Analysis. Laryngoscope, 125, 92-98. https://doi.org/10.1002/lary.24883

[28] Youssef, T.A., Elibiary, H. and Amish, K.F. (2013) Role of Steroids in Reducing Postoperative Edema in Rhinoplasty: A Meta-Analytic Study. European Archives of 
Oto-Rhino-Laryngology, 270, 1189-1193.

https://doi.org/10.1007/s00405-012-2144-y

[29] Gutierrez, S. and Wuesthoff, C. (2014) Testing the Effects of Long-Acting Steroids in Edema and Ecchymosis after Closed Rhinoplasty. The Canadian Journal of Plastic Surgery, 22, 83-87. https://doi.org/10.1177/229255031402200213

[30] Kayiran, O. and Calli, C. (2016) The Effect of Periorbital Cooling on Pain, Edema and Ecchymosis after Rhinoplasty: A Randomized, Controlled, Observer-Blinded Study. Journal of Rhinology, 54, 32-37. https://doi.org/10.4193/Rhin15.177

[31] Ozucer, B., et al. (2016) Effect of Postrhinoplasty Taping on Postoperative Edema and Nasal Draping a Randomized Clinical Trial. JAMA Facial Plastic Surgery, 18, 157-163. https://doi.org/10.1001/jamafacial.2015.1944

[32] Al Arfaj, A.M. (2015) The Use of Nasal Packing Post Rhinoplasty: Does It Increase Periorbital Ecchymosis? A Prospective Study. Journal of Otolaryngology_Head \& Neck Surgery, 44, Article No. 22. https://doi.org/10.1186/s40463-015-0075-5 